\title{
TRABAJO SOCIAL E INMIGRANTES. LAS INTERVENCIONES DEL TRABAJO SOCIAL
}

\section{OCTAVIO VÁZQUEZ AGUADO}

Profesor del Departamento de Sociología y Trabajo Social. Universidad de Huelva.

Miembro de Andalucía Acoge.

\section{MERCEDES GONZÁLEZ VÉLEZ}

Profesora del Departamento de Sociología y Trabajo Social. Universidad de Huelva.

\begin{abstract}
Este artículo fue presentado como comunicación al I Congreso de Escuelas de Trabajo Social, celebrado en Valencia los días 8, 9 y 10 de abril de 1996. Recoge la reflexión y experiencia adquirida en un grupo de formación de la Federación Andalucía Acoge, desarrollado conjuntamente con el Centro de Bruselas de Acción Intercultural, bajo la iniciativa europea Horizon.
\end{abstract}

\section{INTRODUCCIÓN}

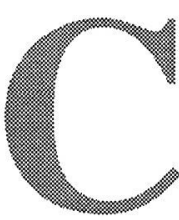

uando nos planteamos la relación de ayuda con los inmigrantes siempre analizamos en profundidad uno de los dos actores que intervienen en dicho proceso (el inmigrante). Sin embargo, nosotros consideramos que es imposible comprender en profundidad lo que ocurre en la relación de ayuda si sólo se analiza uno de sus actores, es decir, que es necesario plantearnos también qué ocurre con nosotros (los trabajadores sociales), cómo nos posicionamos frente a una persona que tiene unos registros culturales distintos, cómo influyen esos registros, qué aspectos de nuestra visión de la vida se ven amenazados y por qué ante esta presencia. En definitiva, cuáles son las especificidades que hay que estudiar y manejar en la relación de ayuda con personas de distintas culturas.

El Trabajo Social está forjado en una corriente cultural y de pensamiento donde prevalece un sentido individual por encima de uno comunitario, donde se resta importancia a lo religioso en la vida de las personas y donde la pauta general tiende hacia la homogenización que elude las diferencias entre los miembros de una sociedad. 
Por ser un producto cultural de una sociedad dada, en este caso la occidental, el Trabajo Social va a estar recorrido por los valores propios de esta sociedad: la igualdad, la secularización, el individuo..., sin embargo, no son estos los valores que caracterizan a las sociedades de donde proceden los inmigrantes, por lo que, en la relación de ayuda, se va a producir una violencia simbólica que puede influir en el resultado de nuestra acción. ¿Cómo manejamos este conflicto?

\section{ELEMENTOS A TENER EN CUENTA EN EL PROCESO DE AYUDA DEL TRABAJO SOCIAL CON INMIGRANTES}

Antes de comenzar, hay que decir que la relación de ayuda y el proceso de ayuda son los elementos definitorios del Trabajo Social como profesión. Los Trabajadores Sociales intentamos mejorar las situaciones de carencia que se nos presentan, buscando que sea la propia persona el protagonista de ese proceso; queremos que se implique, que decida por sí misma, que las soluciones que buscamos respondan a sus propios recursos, que se ajuste a su realidad...

Cuando trabajamos con inmigrantes, todo el proceso de ayuda parte de las premisas anteriores: hay que respetar a las personas, su visión del mundo, sus sistemas de valores, sus necesidades y el orden de las mismas. No imponer un modelo social determinado, sino que sea la propia persona la que decida qué modelo quiere para su vida. En definitiva, se trata de respetar las diferencias, que consiste en el respeto a la identidad sociocultural (religión, etnia, clase social, valores...) desde un punto de vista dinámico y no estático, es decir, siendo conscientes de que se trata de una identidad en evolución y en cambio.

¿Qué podemos entender como interculturalidad en la relación de ayuda? Básicamente, la interrelación entre dos identidades que se dan mutuamente sentido en un contexto que hay que definir cada vez. Es decir, es una relación entre dos individuos que se influyen mutuamente, por lo que el Trabajo Social tendrá que ser consciente de que la diferencia se construye a partir de la identidad propia, entre su cultura y la del otro. Por otro lado, que haya que definirla cada vez hace referencia a que la relación no está libre de las influencias del contexto.

Hay otro factor importante a tener en cuenta: el Trabajador Social y el inmigrante pertenecen a dos identidades diferentes, pero una de ellas ocupa una posición de superioridad (Trabajador Social) y otra de inferioridad (inmigrante), una valorada y otra no, lo que va a implicar estrategias a la defensiva por ambas partes: el Trabajador Social estará alerta para no admitir conductas que no se ajustan a la igualdad, a los derechos de los niños..., y el inmigrante intentará conseguir lo que bus- 
ca sin renunciar a su identidad. Estas relaciones ponen de manifiesto el conflicto de poder entre el Trabajo Social y el inmigrante, y también entre los pueblos y las culturas que ambos representan.

En definitiva, tres van a ser los elementos que van a intervenir en la relación de ayuda con inmigrantes:

- la cultura de cada uno,

- la interacción entres dos actores,

- las diferencias de estatus social, político y económico. El poder.

Por tanto, no basta con conocer la cultura del otro, hay que ser conscientes de la cultura propia, de los prejuicios, las preconcepciones, las imágenes guía, que son filtros que van a mediatizar claramente nuestra relación profesional con los migrantes, ya que van a orientar nuestra percepción sobre conductas de personas con registros distintos. Ser conscientes de cuáles son nuestras zonas sensibles, aquello que nos produce rechazo porque no se ajusta a nuestra forma de ver el mundo. Estas zonas sensibles van a girar, fundamentalmente, en torno a: la representación de la familia (cómo es, cómo se constituye, qué papel juega), el rol y estatus de la mujer (la igualdad con los hombres, su papel en la sociedad), el concepto de persona (el individuo frente al grupo), el papel de la religión, aspectos sobre los que van a girar la mayoría de los conflictos entre trabajadores sociales e inmigrantes.

¿Cómo se manifiestan estos conflictos? ¿Cómo aparecen? ¿Cómo abordarlos?

Para estudiar esta cuestión nada mejor que ejemplificarla con el siguiente relato, protagonizado por una Trabajadora Social de 25 años, miembro de una asociación de ayuda al imnigrante, que nos cuenta lo siguiente:

«Me invitaron a comer un grupo de senegaleses para celebrar que uno de ellos había obtenido su permiso de trabajo y residencia. A la hora convenida, vinieron a recogerme al trabajo. Habitan una casa, de unos $40 \mathrm{~m}^{2}$, donde viven 10 personas, con dos habitaciones, cocina y cuarto de baño. Todos ellos se dedican a la venta ambulante. Cuando llegué a ella, la comida ya estaba hecha, pero mi sorpresa fue que me metieron en un dormitorio, me sentaron en una cama, me dieron un plato y una cuchara y me dejaron sola. Ellos se fueron a comer a la cocina, sentados en el suelo, con un plato para todos del que comieron con las manos.

No supe qué hacer. Me sentí muy violenta. Quería irme».

Este es un ejemplo de choque cultural, es decir, una confrontación de dos culturas distintas sobre los mismos hechos y situaciones. Generalmente, generan incomprensión, indignación... ¿Cómo se comportan así, cómo pueden hacer eso...?

Estos choques se producen porque nosotros esperamos que todos se comporten como nosotros lo haríanos. Nos puede servir para ver 
como, sin necesidad de querer ofender o molestar, hay comportamientos culturales que, si no se conocen, generan malestar en el otro. A estos choques se denominan incidentes críticos o choques culturales.

Se analizan a partir de un instrumento, el análisis de los incidentes críficos o choques culturales, que sirve para situarnos ante una reacción o comportamiento que no entendemos, teniendo como objetivo analizar el hecho sucedido a partir de estudiar y conocer en nuestra cultura qué significa lo ocurrido y cómo tendríamos que actuar $y$, por otro lado, conocer lo que significa en la cultura del otro y el porqué de los comportamientos que determina.

Por lo tanto, es un método que sirve para mejorar el conocimiento que tenemos de nuestra propia cultura y la del otro. Pero no sirve para resolver casos concretos, para ello se utiliza el estudio de casos y la negociación intercultural.

\section{CÓMO SE DESARROLLA EL MÉTODO'}

El método consta de un total de 10 cuestiones que afectan a cuatro aspectos generales a partir de los cuales se desarrolla el incidente crítico. Veamos cada uno de ellos.

\subsection{Los actores y sus relaciones}

En este aparado se persigue conocer tres cuestiones básicas:

- Quiénes son los actores presentes en esta situación intercultural, sus identidades: años, sexo, origen, profesión...

- Qué tipo de relaciones existen entre ellos... Quién ocupa una posición «alta» y otra «baja»...Quién aporta a quién.

- Qué relación existe entre los grupos de pertenencia de los principales actores: contencioso histórico...

Como se puede apreciar, en esta primera parte, se persigue el conocimiento en profundidad de los actores del incidente, la relación que tienen entre ellos y entre sus grupos de pertenencia. En ocasiones, este apartado sirve para descubrir qué posición ocupamos frente al otro, cómo nos valora éste y también para que reflexionemos sobre cómo percibimos al otro.

Este método ha sido desarrollado por Margalit Cohen-Emerique, del laboratorio de Psicología Social aplicada de la Universidad París V y ha sido adaptado por Javier Leunda, miembro del Centro de Bruselas de Acción Intercultural, para el Curso de Formación de Formadores de la Federación de Andalucía Acoge desarrollado en los años 1994-1996. 


\subsection{La situación de choque}

Descrita en base a:

- la situación en la que se desarrolla la escena: contexto físico, social, psicológico, político...

- la relación de choque: sentimientos vividos y los comportamientos que se han derivado de la situación de choque.

\subsection{El esquema de referencia}

Consiste en conocer bajo qué premisas se desarrolla el comportamiento de los actores presentes para comprender así el comportamiento de uno y la extrañeza del otro. Es la parte central del método y se desarrolla de acuerdo a:

- Describir en torno a qué gira la situación, señalar los elementos claves, es decir, sobre qué se produce el incidente.

- Conocer, indagar en el marco de referencia de la persona que ha contado el incidente: por qué se extraña, cuál es su visión del incidente y por qué, qué sería para ella lo correcto y por qué.

- Qué imagen se vislumbra del otro grupo, es decir, qué piensa la persona que ha narrado el incidente sobre la otra persona, su grupo de referencia, su cultura.

- Conocer el marco de referencia del otro, es decir, por qué se ha comportado así, cuáles son las pautas de comportamiento en su cultura de origen, cómo se vive la situación sobre la que gira el hecho... En definitiva, conocer al otro.

\subsection{Después del hecho}

Este es el último apartado del método e intenta facilitar una reflexión sobre cómo quedan las relaciones entre los actores del incidente, para ello sugiere reflexionar sobre las cuestiones a las que afecta el choque cultural: a la práctica profesional, a los valores personales..., en definitiva, quiere incidir en las dificultades que tiene un respeto activo a las diferencias culturales.

Como se ve, es un método que analiza en profundidad tanto el marco de referencia del informante como el de la otra persona, por lo que será imprescindible, a la hora de desarrollarlo, contar con la persona que sufrió el incidente, pero también con un informante de la cultura del imnigrante para conocer qué significa lo ocurrido en dicha cultura.

Veamos ahora cómo incardinar este método en el proceso de ayuda con inmigrantes. 


\section{EL ACERCAMIENTO INTERCULTURAL EN EL PROCESO DE AYUDA DEL TRABAJO SOCIAL. FASES Y SU DESARROLLO}

\subsection{La descentración}

Consiste en tomar distancia de uno mismo para reflexionar sobre nosotros como sujetos portadores de cultura, de nuestra identidad social y profesional, siendo consciente de que los prejuicios y los estereotipos son propios del hombre, por tanto, no hay que culpabilizarse.

La descentración no se hace en abstracto; se hace a partir de un hecho concreto. Para ello, podemos utilizar el método de los incidentes críticos visto con anterioridad. Este método sirve como revelador de nosotros mismos, es como un espejo en el que nos miramos a partir de un hecho que nos choca, y por el que podemos llegar a acceder a nuestros propios esquemas de referencia.

Dentro de la descentración, es importante que:

- Desconfiar de las primeras impresiones como una sana medida de precaución, sobre todo, cuando las diferencias culturales son importantes.

- Hacer emerger las «imágenes-guía» (las preconcepciones, los valores que orientan nuestra percepción), a través de las cuales son interpretadas y evaluadas muchas situaciones profesionales. Las principales afectan a la visión de: los roles masculinos y femeninos, la educación del niño, la vida familiar, la importancia de la religión, la concepción del tiempo y del espacio, la relación con el cuerpo.

- Reflexionar sobre sus presupuestos, sobre lo que hay detrás de nuestra percepción de los choques culturales, para poder así relativizarlos y conocer qué es lo que hay realmente detrás. En definitiva, poner de manifiesto nuestras evidencias.

\subsection{Penetrar en el sistema del otro}

Esta es la segunda fase, que consiste en intentar comprender al otro, el porqué de su comportamiento, a qué responde. Exige una actitud de apertura, de curiosidad.

Para poder comprender el sistema del otro podemos seguir las siguientes estrategias:

- Informarse mediante lecturas, conversaciones con informadores claves que conozcan su cultura. Pero es insuficiente si nos limitamos a adquirir un saber objetivo, que no nos permite comprender a la persona individual, con la que tendríamos que establecer una comunicación que vaya más allá de la simple recopilación de información. La verdadera comunicación es el punto de partida para el reconocimiento del otro. 
- La escucha del otro, pero sin interpretarlo, sin buscar los móviles de su conducta. Esto es importante si tenemos en cuenta que la comunicación se va a producir en el idioma de la sociedad de acogida, que no sirve para expresar los senfimientos más profundos $y$, generalmente, no se conoce en profundidad. Ante ello, debemos preguntar por el sentido de las palabras. Estar atentos también a las palabras claves, las que se repiten y ver qué sentido tienen para el que habla.

- Conocer y deber interpretar la comunicación no verbal para contemplar el contexto donde se produce la relación, portadora también de información. Esto significa que hay que aprender a observar, a estar atento a los detalles portadores de sentido (vestido, objetos, expresión de las manos...).

Por último, dos recomendaciones generales: una, viajar, para ver al otro en su contexto; dos, tomarse tiempo. Acercarse al otro para interpelarle e interpelarnos exige un proceso de maduración que lleva tiempo.

Hasta ahora ya hemos intentado comprender y conocer un poco más por qué son significativos o chocantes algunos actos para nosotros. También hemos intentado comprender qué significan para el otro. Pero esto no es suficiente. Hay que entrar en relación y, para que sea fructífera y útil, hay que entrar en un proceso de negociación y mediación.

\subsection{Negociación y mediación}

Para los trabajadores sociales que se dedican a la resolución de problemas, la negociación y la mediación son fases definitivas para alcanzar tal fin.

Si el presupuesto del que partimos es que hay que respetar las diferencias culturales en su integridad, cuando entran en relación dos culturas distintas, ¿hasta dónde hay que respetar las diferencias sin que eso suponga atentar contra la propia identidad?

Aterrizando en cuestiones concretas con las que nos podemos encontrar: ¿hay que respetar que un padre pegue a un niño que le ha faltado al respeto? Para el padre, el niño ha roto una ley fundamental en su cultura, que es el respeto a los mayores; para nosotros, la actuación del padre atenta contra los derechos del niño. Así existen un montón de situaciones. ¿Qué hacer con ellas?

No hay una respuesta global para este tipo de cuestiones. Cada una de ellas exige una respuesta propia. Esa respuesta vendrá a través o de la negociación, que consistirá en asegurar una serie de intercambios, de puntos de vista, para llegar a acuerdos concretos, o través de la mediación, que consiste en intervenir para poner de acuerdo a dos par- 
tes, de encontrar un terreno común donde ambas identidades puedan vivir, sin que ello implique que una de las dos renuncie a ser lo que es o que se quede como está, tomando una postura de indiferencia.

Encontrar ese mínimo de compromiso, ese espacio común donde es posible la convivencia, no es fácil, ya que se trata de encontrar los límites que ninguno de los dos protagonistas puede superar, ya que, en el caso de los inmigrantes, o perderían su identidad o se verían relegados a una posición de marginación, y, en el caso de los Trabajadores Sociales, faltarían a su misión profesional.

Veamos las condiciones previas para poder realizar la negociación o la mediación:

$1^{a}$. Reconocer que se trata de un conflicto de valores entre el inmigrante y la sociedad de acogida (representada por el profesional), que no se trata de conductas aberrantes que hay que abolir.

$2^{a}$. Considerar al inmigrante como igual a nosotros, en el sentido de valorar su punto de vista y su poder para aportar soluciones. No imponer una solución desde fuera que, seguramente, generará mas violencia.

$3^{\mathrm{a}}$. Que la aproximación hay que hacerla en los dos sentidos para que se produzca un cambio en ambos lados. Esto exige que el profesional se tiene que acercar al otro, no esperar siempre a que venga a nosotros. No pensar que es el otro el que siempre tiene que cambiar.

Con estas prermisas, la negociación tiene que contemplar una presentación, donde el profesional tiene que tender a personalizar, sin que ello suponga comunicar datos íntimos. Esta personalización ayudará a establecer la relación, que se sostendrá con un clima de empatía, de compresión del otro. Para ello, es importante estar atento a las palabras claves, a las que más se repiten, en las que se ponga más énfasis. Así mismo, es recomendable preguntar por lo que se desconoce.

Como se trata de una negociación, es importante dedicar tiempo a aclarar el objetivo común que se persigue. En la medida que se le reconoce al otro capacidad influir, autoridad para establecer dicho objetivo, éste reconocerá que se le tiene en cuenta y habrá una mayor disposición a entrar en la negociación.

Por último, en la negociación será importante introducir elementos que ayuden al mantenimiento de la relación.

Esta aproximación intercultural no está exenta de problemas y de límites. Veamos algunos de ellos:

- De orden cultural, ya que la comprensión de códigos muy alejados a los propios es difícil, máxime cuando la intervención de los profesionales se hace, casi siempre, en situación de crisis.

- De orden, institucional, que marca los límites a la actuación de los profesionales y que responden a un determinado orden cultural. 


\section{PARA FINALIZAR}

La relación y la mediación intercultural no están exentas de problemas y dificultades tanto de orden metodológico como personal, en la medida que se reconoce que no es sólo la identidad del otro la que está en juego sino también la propia. A pesar de ello, creemos que es la alternativa más respetuosa con todos los actores que intervienen. Quizá baste reconocer que no siempre los raros son los otros. 